\title{
A statistical model for dew point air cooler based on the multiple polynomial regression approach
}

\author{
Yousef Golizadeh Akhlaghi ${ }^{a}$, Xiaoli Ma ${ }^{\mathrm{a}, * *}$, Xudong Zhao ${ }^{\mathrm{a},{ }^{*}}$, Samson Shittu ${ }^{\mathrm{a}}$, \\ Junming $\mathrm{Li}^{\mathrm{b}}$ \\ a School of Engineering and Computer Science, University of Hull, Hull, HU6 7RX, UK \\ ${ }^{\mathrm{b}}$ Department of Thermal Engineering, Tsinghua University, Beijing, 100084, China
}

\section{A R T I C L E I N F O}

\section{Article history:}

Received 19 January 2019

Received in revised form

7 May 2019

Accepted 29 May 2019

Available online 3 June 2019

\section{Keywords:}

Dew point cooling

Multiple polynomial regression

Operational parameters

Performance parameters

Statistical model

\begin{abstract}
A B S T R A C T
Swift assessment of evaporative cooling systems has become a necessity in practical engineering applications of this advanced technology. This paper bypasses details of the performance process and pioneers in developing a statistical model based on the multiple polynomial regression (MPR) to predict the performance of a dew point cooling (DPC) system. Thousands of numerical and experimental data are explored and the statistical model is produced. The developed statistical model correlates the performance parameters with the key operational parameters, including the flow and geometric characteristics. The selected operational parameters are, intake air conditions, including temperature, relative humidity and flow rate as well as the working air fraction over the intake air, while cooling capacity, coefficient of performance (COP), pressure drop, dew point and wet-bulb effectiveness are selected as performance parameters. The considered geometric characteristics are channel height, channel interval and number of layers in heat and mass exchanger. The model with different polynomial degrees is assessed by R2, MRE and MSE metrics. The 8th degree polynomial model is selected. The maximum relative error of the cooling capacity, coefficient of performance, pressure drop, dew point and wet-bulb effectiveness are $6.1 \%, 7.54 \%, 0.07 \%, 3.54 \%$ and $2.53 \%$ respectively. Finally, as examples, the model is used to predict the performance of the DPC system in random operating conditions and in a dry climate i.e. Las Vegas. Model developed in this study would enable the swift prediction of the DPC system.
\end{abstract}

(C) 2019 Elsevier Ltd. All rights reserved.

\section{Introduction}

Indirect Evaporative Cooling (IEC) employs the advantage of water evaporation to decrease the air temperature without increasing the absolute humidity [1]. A new generation of the IEC, Dew Point Cooling (DPC), can decrease the temperature of the air down to its dew point, and thus achieves higher cooling efficiency than the conventional IEC. This energy efficient technology is established on a M-cycle heat and mass exchanger which basically has the cross-flow or counter-flow types [2]. DPC with a wellstructured heat and mass exchanger (HMX) pre-cools the working air (or secondary air) prior to its diversion into the wet channels; this practice can decrease both dry bulb and dew point temperatures of the air within the wet channels, thus achieving

\footnotetext{
* Corresponding author.

** Corresponding author.

E-mail addresses: x.ma@hull.ac.uk (X. Ma), xudong.zhao@hull.ac.uk (X. Zhao).
}

20-30\% higher cooling efficiency compared to the conventional IECs. Significant achievements have been made in numerical simulations and experimental testing of the DPC.

Through experimental studies, performance comparison of a Mcycle a counter-flow and cross-flow heat exchangers for IECs has been progressed by Zhan et al. [3]. It was found that cooling capacity of the M-cycle counter-flow DPC is 20\% higher, dew point efficiency and wet bulb efficiency were $15 \%-23 \%$ higher than that of the cross flow DPC. Whereas the COP is $10 \%$ lower than that of the cross flow cooler. A test carried out by Xu et al. [4] indicated the DPC prototype achieved the wet-bulb cooling effectiveness of $114 \%$ and dew-point cooling effectiveness of $75 \%$, yielding a significantly high COP value of 52.5 at the optimal working air ratio of 0.364 . Bruno [5] tested a prototype dew point cooler in both commercial and residential applications and presented the performance characteristics of the system. B. Riangvilaikul, S. Kumar [6] conducted and experimental study on a DPC where the results showed that the wet bulb effectiveness is in the ranges of 92 and $114 \%$ and the dew 


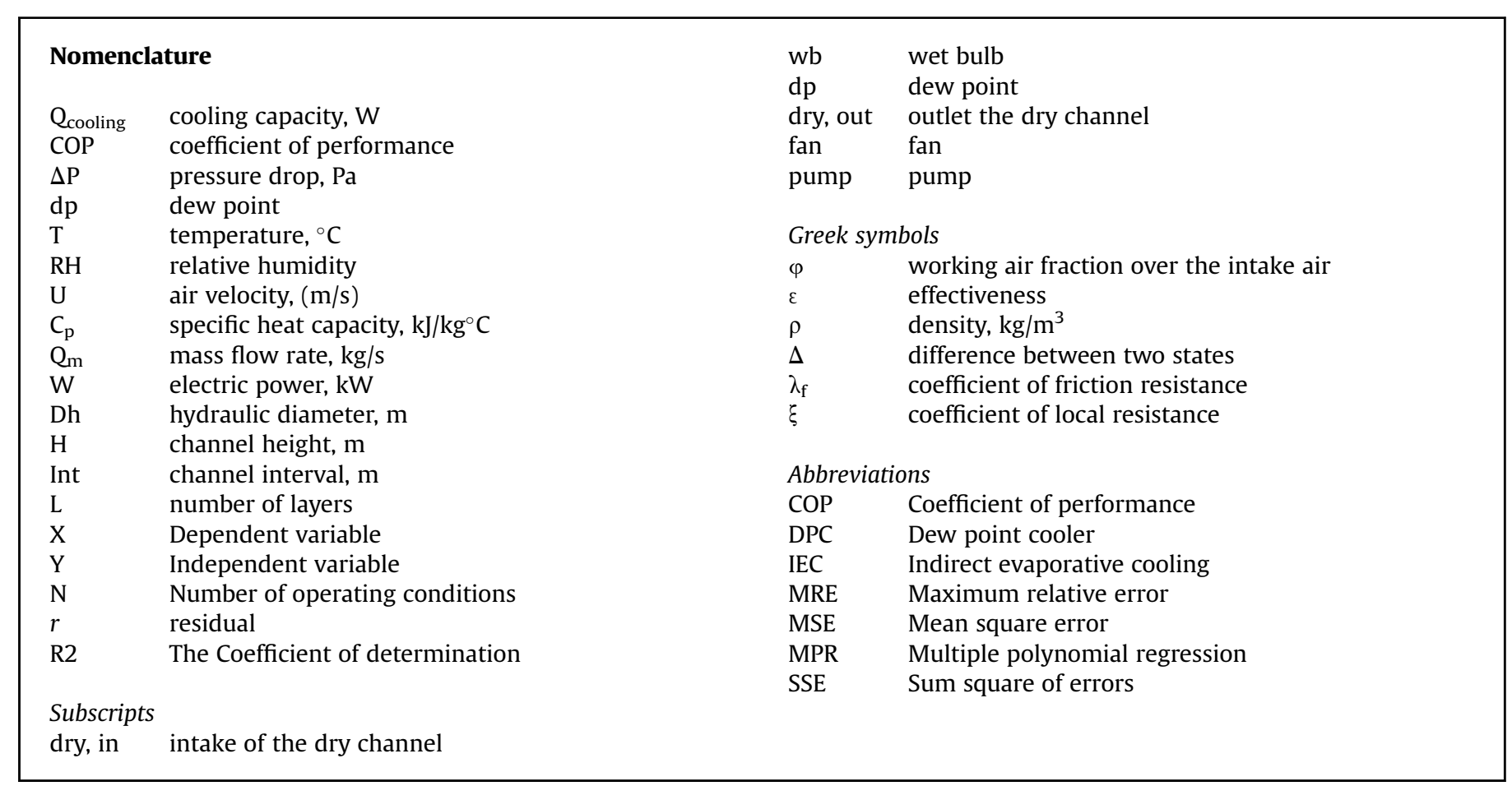

point effectiveness is between 58 and $84 \%$.

Among the numerical studies, Zhao et al. [7] found that the performance of the DPC is greatly affected by the dimensions of the airflow passages, air velocity and working-to-intake-air ratio. Cui et al. [8] conducted a model on a novel counter flow DPC and the results indicated that the system achieves higher efficiencies with lower air velocity, smaller channel height, larger length-to-height ratio, and lower product-to-working air flow ratio. Lin et al. [9] developed a transient model for the counter-flow DPC which could predict the product air temperature with maximum error of $4.3 \%$. $\mathrm{Xu}$ et al. [10] established a novel super performance DPC, by removing the use of the channel supporting guides and implemented the corrugated heat transfer surface, to indicate that compared to the existing flat-plate HMXs with the same geometrical dimensions and operational conditions, the new novel irregular exchanger for DPC could achieve 32.9\%-37\% higher cooling capacity, dew-point and wet-bulb effectiveness, 29.7\%-33.3\% higher COP, and 55.8\%-56.2\% lower pressure drop. D. J. Lin et al. [11] presented an improved numerical model for the DPC and revealed significant achievements. B. Riangvilaikul, S. Kumar [12] studied the performance of a DPC system under various inlet air conditions. Y. Wan et al. [13] compared two DPC with different air flow configurations with maximum error of $6.0 \%$. J. Lin et al. [14] developed an experimental and numerical study to investigate the convective heat and mass transfer process of a DPC. In another study J. Lin et al. [15] developed a model to deeply investigate the governing factors of a DPC with maximum discrepancy of $8 \%$.

The review of all studies for DPCs endorses the great achievements in numerical simulation and experimental testing of a superperformance DPC. However, an apparent gap is still in existence between the research findings and engineering application of this advanced technology. The current numerical and experimental data are limited to the narrow data scales and also are expressed in one-to-one parametrical correlative forms. This situation has largely obstructed the wide and rational application of DPC technology in practical engineering in which multiple parameters vary simultaneously across wide ranges of data scales. Furthermore, cost of constructing the test rigs is an outstanding disadvantageous in experimental study. Even though the numerical studies are economic, they often include complicated and differential equations and it is quite time consuming to use them.

Therefore, to overcome the above-mentioned problems, some studies have proposed statistical methods to evaluate the performance of evaporative coolers. Pandelidis and Anisimov [16] used response surface methodology (RSM) for the Maisotsenko cycle heat and mass exchanger. Four performance factors including outlet temperature, specific cooling capacity, dew point effectiveness, and the theoretical COP were selected. Cui et al. [17] evaluated the thermal performance of a counter-flow regenerative IEHX (indirect evaporative heat exchanger) by developing a performance correlation based on the non-dimensional forms of the governing equations. Sohani et al. pioneered in employing several statistical methods i.e. artificial neural network (ANN), group method of data handling (GMDH), genetic programming (GP), multiple linear regression (MLR), and stepwise regression method (SRM) to optimize [18] and compare [19] the IECs. Also, he analyzed desiccant enhanced evaporative cooling systems [20] and cellulose evaporative cooling pad systems [21], and found the best roadmap to improve the power plants [22] with DPCs. Comino et al. [23] developed a simplified model of cross flow IEC systems based on collected experimental data. H. Sadighi Dizaji et al. [24] developed an analytical model for three-stage regenerative M-cycle exchanger. A. López-Belchí et al. [25] used Artificial Neural Networks (ANN) coupled with Group of Method Data Handling (GMDH) for the mini-channels. A. Pakari and S. Ghani [26] regression models are developed for counter flow dew point evaporative cooling systems using numerical simulations and response surface methodology.

Regression is a popular statistical method among the researchers since it performs as a predictive tool to investigate the relationship between dependent parameters and independent parameters. Additionally, regression method has numerous areas of 
Table 1

Various classifications of regression analysis.

\begin{tabular}{|c|c|}
\hline Type of Regression & Definition \\
\hline Univariate/Multivariate & Only one/two or more quantitative dependent variables \\
\hline Simple/Multiple & Only one/two or more independent variables \\
\hline Linear & All parameters appear in the equation linearly \\
\hline Nonlinear & $\begin{array}{l}\text { The relationship between the dependent variable and some of the } \\
\text { independent variables is nonlinear }\end{array}$ \\
\hline Polynomial Regression & $\begin{array}{l}\text { The relationship between the dependent variable and independent } \\
\text { variable can be expressed by a polynomial function }\end{array}$ \\
\hline Stepwise regression & $\begin{array}{l}\text { Builds a model by adding or removing the predictor variables, } \\
\text { generally via a series of T-tests or F-tests }\end{array}$ \\
\hline Logistic Regression & $\begin{array}{l}\text { It is used to predict the probability of an event where } \\
\text { the result is binary that is either yes or no }\end{array}$ \\
\hline
\end{tabular}

applications such as engineering, physics and chemical science [27], medicine [28], etc.

This research pioneers in bringing the multiple polynomial regression (MPR) to develop a statistical model which performs as a predictive tool for assessing the performance of the DPC with a novel irregular heat and mass exchanger in different operating conditions. The developed model is presented in the form of polynomial equations which directly correlates the main operational parameters (i.e., intake air temperature, intake air relative humidity, intake air flow rate and working air fraction over the intake air) to the performance parameters of the DPC (i.e. cooling capacity, coefficient of performance, pressure drop, dew point effectiveness and wet-bulb effectiveness) by considering the selected geometric parameters (i.e. channel height, channel interval and number of layers). Additionally, the model is needless of complicated heat, mass and associated auxiliary equations and iteration processes.

The remaining part of this paper is structured as follows; section 2 provides a detailed statistical model description and development. Section 3 describes the results obtained from this study including the model validation, assessment and application of the model. Eventually, section 4 describes the conclusion drawn from this study.

\section{Multiple polynomial regression model}

MPR is one of the numerous regression methods which some common types i.e. polynomial, stepwise and logistic are summarized in Table 1. Main focus of the multiple regression is on analyzing the relationship between one dependent variable and more than one independent variables [29]. The term linear and nonlinear describes the fact that the regression variables appear in the approximated equation linearly or nonlinearly [30]. Additionally, the regression model is called polynomial when the relationship between the dependent and independent variables is represented by a curve. In this study, the MPR is selected to develop the statistical model for multiple independent variables.

\subsection{Mathematical development}

In order to develop a regression model, discrete values for independent variable and dependent variables are needed to formulate the relationship between them. A real value of dependent variable can be represented by $Y$ and independent variables are represented by $\mathrm{X}_{1}, \mathrm{X}_{2}, \mathrm{X}_{3}, \ldots, \mathrm{X}_{\mathrm{p}}$ where $\mathrm{p}$ represents the number of independent variables. The fitted regression function can be expressed as:

$\mathrm{Y}=\mathrm{f}\left(\mathrm{X}_{1}, \mathrm{X}_{2}, \mathrm{X}_{3}, \ldots, \mathrm{X}_{\mathrm{p}}\right)$
A fitting method must be used to fit a model and calculate the estimated values by the regression model based on the collected data. The most commonly used method of estimation is called the least squares method. To fit a set of data base, the least-squares method minimizes the sum of squared residuals as presented in Equation (2). The residual or sum square of errors (SSE) is the difference between the actual values and the estimated regression values which is denoted by $r_{i}$.

$S S E=\sum_{i=0}^{N}\left(\widehat{\mathrm{Y}}_{\mathrm{i}}-\mathrm{Y}_{\mathrm{i}}\right)^{2}=\sum_{i=0}^{N} r_{i}^{2}$

where, $\widehat{Y}$ represents the predicted value of the dependent variable by regression model and $\mathrm{N}$ represents the number of predicted values. Form of the equation (1) must be chosen considering the selected data and depending on their relationship. The selected MPR employs the polynomial equations to predict the dependent variables. The general form of the linear polynomial equation is:

$\mathrm{Y}=\beta_{0}+\beta_{1} \mathrm{X}+\beta_{2} \mathrm{X}^{2}+\ldots+\beta_{\mathrm{m}} \mathrm{X}^{\mathrm{n}}$

where, $\beta_{1}, \beta_{2}, \ldots, \beta_{\mathrm{m}}$ represent the unknown regression coefficients

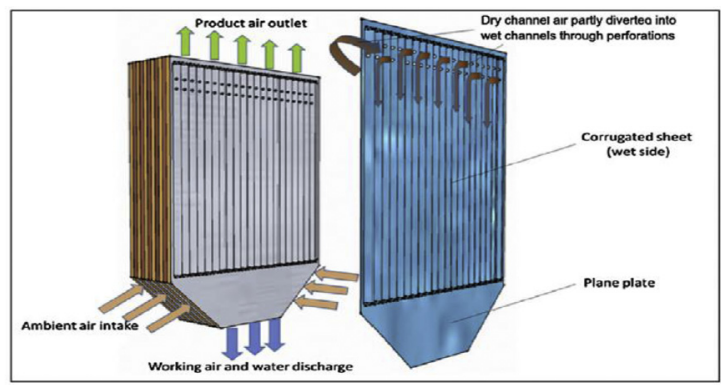

(a) [4]

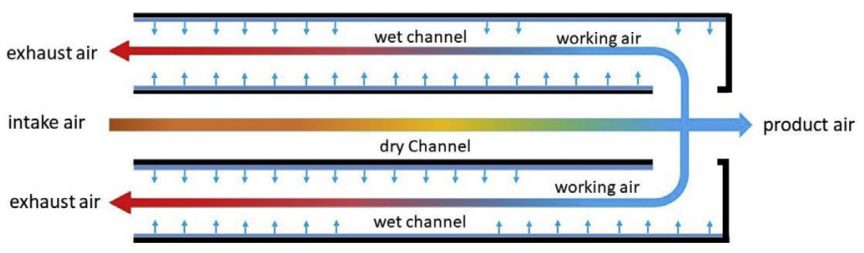

(b)

Fig. 1. Heat and mass exchanger (a): heat and mass exchanger structure (b): Air stream inside the wet and dry channels. 


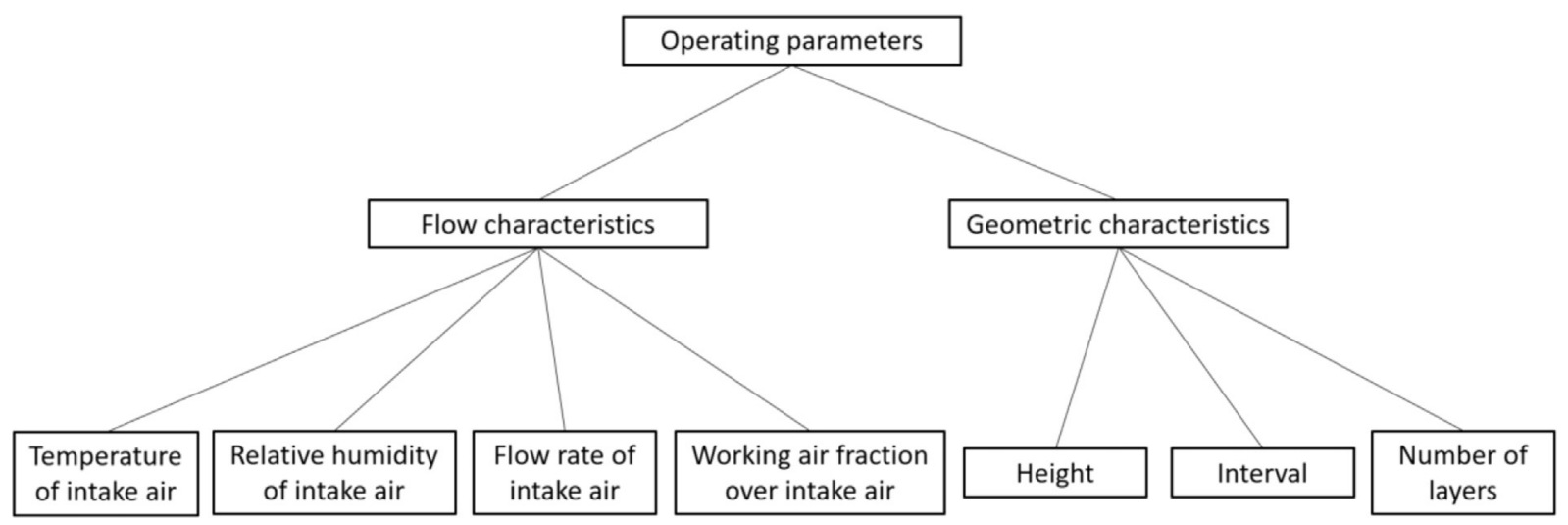

Fig. 2. Operating parameters.

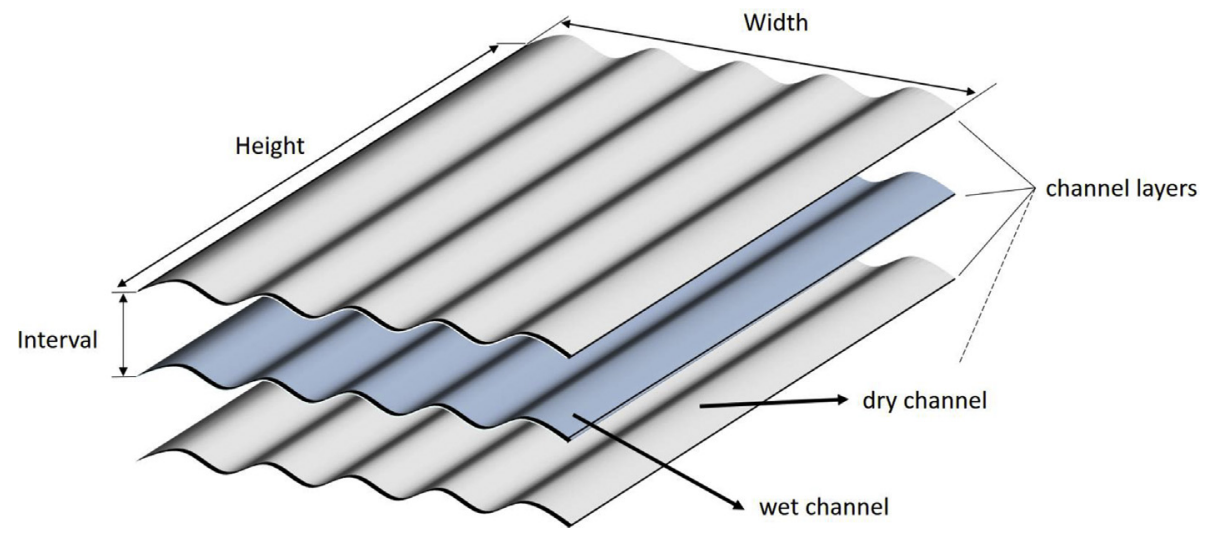

Fig. 3. Schematic of heat and mass exchanger.

which will be calculated using the selected data. Three common metrics are used to evaluate the performance of the polynomial regression: mean square error (MSE), coefficient of determination (R2) and maximum relative error (MRE). The MSE and R2 are defined as:

$\mathrm{MSE}=\frac{\mathrm{SSE}}{\mathrm{N}}=\frac{\sum_{\mathrm{i}=0}^{\mathrm{N}}\left(\widehat{\mathrm{Y}}_{\mathrm{i}}-\mathrm{Y}_{\mathrm{i}}\right)^{2}}{\mathrm{~N}}$

$\mathrm{R}^{2}=1-\frac{S S E}{S S T}=1-\frac{\sum_{\mathrm{i}=0}^{\mathrm{N}}\left(\widehat{\mathrm{Y}}_{\mathrm{i}}-\mathrm{Y}_{\mathrm{i}}\right)^{2}}{\sum_{\mathrm{i}=0}^{\mathrm{N}}\left(\overline{\mathrm{Y}_{\mathrm{i}}}-\mathrm{Y}_{\mathrm{i}}\right)^{2}}$

where SST is sum square of total, $\bar{Y}$ is the mean of predicted value.

Table 2

Range of operating parameters in MPR.

\begin{tabular}{lll}
\hline Type of parameters & Operating parameters & Range \\
\hline Flow characteristics & $\mathrm{T}\left({ }^{\circ} \mathrm{C}\right)$ & $25-45$ \\
& $\mathrm{RH}(-)$ & $0.125-0.5$ \\
& $\mathrm{U}(\mathrm{m} / \mathrm{s})$ & $0.3-3.3$ \\
& $\phi(-)$ & $0.1-0.9$ \\
Geometric characteristics & $\mathrm{H}(\mathrm{m})$ & $1-3$ \\
& $\mathrm{Int}(\mathrm{m})$ & $0.004-0.008$ \\
& $\mathrm{~L}(-)$ & $100-200$ \\
\hline
\end{tabular}

\subsection{Development of multiple polynomial regression model}

\subsubsection{The novel super performance dew point cooler}

In this section, the explanation of a selected counter flow DPC is provided. A counter flow DPC is normally constituted of a heat and mass exchanger, product and exhaust air fans, water supply and distribution system (such as water distributor, circulating water pump, water tank and tap water piping, etc.). Among which, the heat and mass exchanger is the key part of a DPC. The schematic drawing of the heat and mass exchanger of the novel super performance DPC is shown in Fig. 1. The heat and mass exchanger consists of wet channels and dry channels. Two wet surfaces build the wet channel and the adjacent two dry surfaces build the dry channel. The corrugated heat transfer surfaces as replacement of

Table 3

Values of operating parameters in the training set.

\begin{tabular}{lllll}
\hline $\begin{array}{l}\text { No. Of discreet } \\
\text { values }\end{array}$ & $\mathrm{T}\left({ }^{\circ} \mathrm{C}\right)$ & $\mathrm{RH}(-)$ & $\mathrm{U}(\mathrm{m} / \mathrm{s})$ & $\phi(-)$ \\
\hline 1 & 25 & 0.125 & 0.3 & 0.1 \\
2 & 27.5 & 0.17 & 0.7 & 0.2 \\
3 & 30 & 0.22 & 1.1 & 0.3 \\
4 & 32.5 & 0.26 & 1.5 & 0.4 \\
5 & 35 & 0.3 & 1.9 & 0.5 \\
6 & 37.5 & 0.34 & 2.3 & 0.6 \\
7 & 40 & 0.38 & 2.7 & 0.7 \\
8 & 42.5 & 0.42 & 3 & 0.8 \\
9 & 45 & 0.5 & 3.3 & 0.9 \\
\hline
\end{tabular}


Table 4

Values of operating parameters in the validation set.

\begin{tabular}{lllll}
\hline $\begin{array}{l}\text { No. Of discreet } \\
\text { values }\end{array}$ & $\mathrm{T}\left({ }^{\circ} \mathrm{C}\right)$ & $\mathrm{RH}(-)$ & $\mathrm{U}(\mathrm{m} / \mathrm{s})$ & $\phi(-)$ \\
\hline 1 & & & & 0.15 \\
2 & 26.25 & 0.14 & 0.5 & 0.25 \\
3 & 28.75 & 0.19 & 0.9 & 0.35 \\
4 & 31.25 & 0.24 & 1.3 & 0.45 \\
5 & 33.75 & 0.28 & 1.7 & 0.55 \\
6 & 36.25 & 0.32 & 2.1 & 0.65 \\
\hline
\end{tabular}

the traditional flat-plate surfaces leads to the increased heat transfer area [10]. On operation, the intake air enters the dry channel with specified temperature and humidity. While passing the dry channel loses its heat to the adjacent wet channels which leads to significant temperature drop. At the end of the dry channel, the intake air is divided into two parts. The first one leaves the channel as a product air and the second one transfers to the adjacent wet channels as a working air. The working air in the wet channels receives considerable amount of heat transferred from the dry channel and the moisture from the surface of the wet channels as well. Eventually, after completing the heat and moisture transition, the working air leaves the wet channel as an exhaust air with high temperature and moisture.

Compared to the traditional flat plate heat and mass exchanger used in the DPC, the novel heat and mass exchanger has the following distinguished advantages:

- Removal of the channel supporting guides which leads to significantly reduced air flow resistance.

- Implementation of the corrugated heat transfer surface as a replacement of flat-plate surface which leads to increased heat transfer area.

- A super performance wet material layer, i.e., Coolmax-fabric generated a higher water absorption capacity, a higher diffusion area and better evaporation effect.

- The high absorption capacity of the wet material layer created an opportunity to implement the intermittent water supply scheme that can minimize the water usage and water pump power consumption.

As a result, under the standard test condition, i.e. dry bulb temperature of $37.8{ }^{\circ} \mathrm{C}$ and coincident wet bulb temperature of $21.1^{\circ} \mathrm{C}$, the prototype cooler has achieved the wet-bulb cooling
Table 5

Geometric parameters and water status of the heat and mass exchanger in numerical model.

\begin{tabular}{ll}
\hline Parameters & Value \\
\hline Length $(\mathrm{m})$ & 1.2 \\
Width $(\mathrm{m})$ & 0.348 \\
Interval $(\mathrm{m})$ & 0.005 \\
Number of layers & 200 \\
Water temperature $\left({ }^{\circ} \mathrm{C}\right)$ & 16 \\
Water flow rate $(\mathrm{kg} / \mathrm{s})$ & 18 \\
\hline
\end{tabular}

effectiveness of $114 \%$ and the dew-point cooling effectiveness of $75 \%$, yielding a significantly high COP value of 52.5 at the optimal working air ratio of 0.364 , compared to the commercial DPC of the same sizes (52.5 vs. 18) [4].

The above super performance DPC was developed through a numerical simulation using a combined CFD and the finite-element based Newton-iteration model [10] and a $4 \mathrm{~kW}$ lab prototype experimentation work [4], a $20 \mathrm{~kW}$ pre-production system has also been constructed and demonstrated at Sinogreen Ltd in China. Regarding the simulation work, the CFD simulation was carried out to determine the flow resistance $(\mathrm{K})$ factors of various elements within the dry and wet channels of the exchanger, while the finiteelement based Newton-iteration numerical simulation was undertaken to investigate its cooling [10]. The numerical model includes: (1) energy balance equations within a dry element of dry channel; (2) mass balance equations in a wet element of wet channel; (3) energy balance equations of the airflow in the wet element; (4) Conservation equations of water mass between the inlet and outlet of a wet element. (5) Energy balance in a coupled dry \& wet elements and variation of the air's humidity ratio. According to the formula provided by the ASHRAE, standard performance of the IECs can be evaluated using following equations [31]:

$\mathrm{Q}_{\text {cooling }}=\mathrm{C}_{\mathrm{p}}\left(\mathrm{T}_{\mathrm{dry}, \text { in }}-\mathrm{T}_{\mathrm{dry}, \text { out }}\right)(1-\varphi) \mathrm{Q}_{\mathrm{m}, \mathrm{dr}, \text { in }}$

where $\mathrm{Q}_{\text {cooling }}$ is cooling capacity, $\mathrm{C}_{\mathrm{p}}$ is the specific heat capacity, $\mathrm{T}_{\text {dry.in }}$ is the intake air temperature in dry channel, $\mathrm{T}_{\text {dry.out }}$ is the outlet air temperature in the dry channel, $\varphi$ is the working air fraction over the intake air and $Q_{m, d r . i n}$ is mass flow rate of intake air in dry channel.

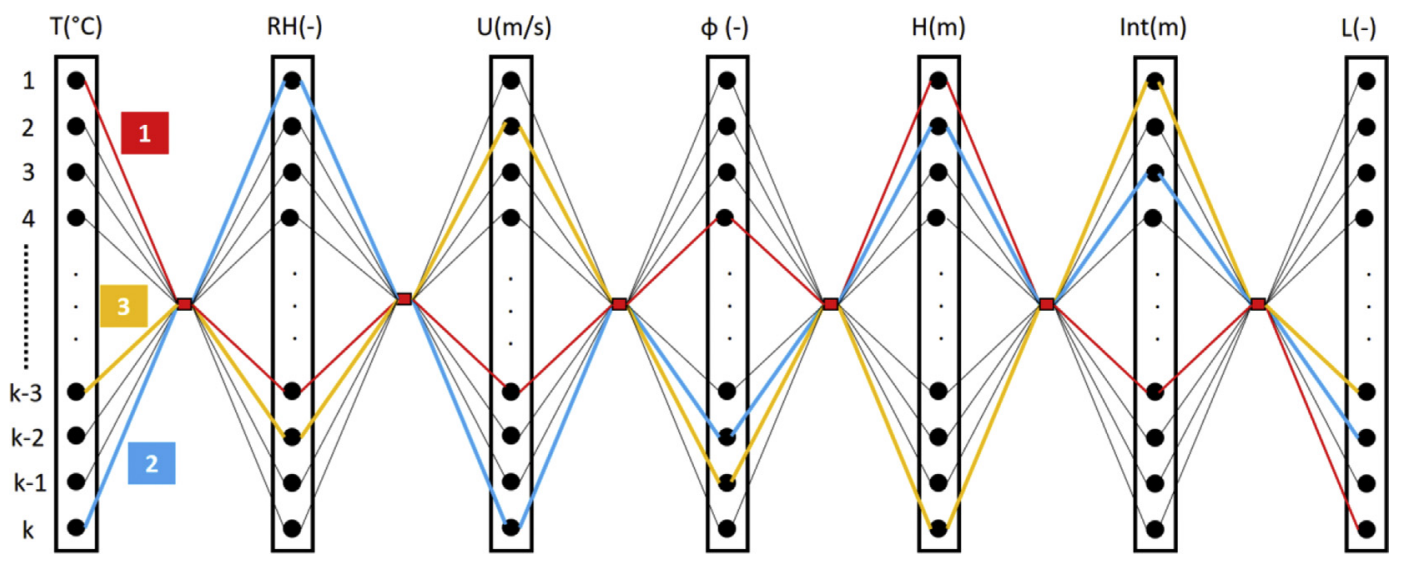

Fig. 4. All possible operating conditions of selected discreet operating parameters. 
Table 6

Discreet values of geometric characteristics for each geometric sets.

\begin{tabular}{|c|c|c|c|c|c|c|c|c|c|c|c|c|}
\hline No. Of sets & 1 & 2 & 3 & 4 & 5 & 6 & 7 & 8 & 9 & 10 & 11 & 12 \\
\hline $\mathrm{H}(\mathrm{m})$ & 1 & 1 & 1 & 1 & 2 & 2 & 2 & 2 & 3 & 3 & 3 & 3 \\
\hline $\operatorname{Int}(\mathrm{m})$ & 0.004 & 0.004 & 0.008 & 0.008 & 0.004 & 0.004 & 0.008 & 0.008 & 0.004 & 0.004 & 0.008 & 0.008 \\
\hline $\mathrm{L}$ & 100 & 200 & 100 & 200 & 100 & 200 & 100 & 200 & 100 & 200 & 100 & 200 \\
\hline
\end{tabular}

$$
\mathrm{COP}=\frac{\mathrm{Q}_{\text {cooling }}}{\mathrm{W}_{\text {fan }}+\mathrm{W}_{\text {pump }}}
$$

where $\mathrm{W}_{\text {fan }}$ and $\mathrm{W}_{\text {pump }}$ are the electrical power consumed by the fan and the pump respectively.

$\varepsilon_{\mathrm{wb}}=\frac{\mathrm{T}_{\mathrm{dry}, \text { in }}-\mathrm{T}_{\text {dry }, \text { out }}}{\mathrm{T}_{\mathrm{dry}, \text { in }}-\mathrm{T}_{\mathrm{dry}, \text { in }, \mathrm{wb}}}$

where $\varepsilon_{\mathrm{wb}}$ is the wet bulb effectiveness and $\mathrm{T}_{\mathrm{dry}, \text { in,wb }}$ is the wetbulb temperature of the intake air in dry channel.

$\varepsilon_{\mathrm{dp}}=\frac{\mathrm{T}_{\mathrm{dry}, \text { in }}-\mathrm{T}_{\mathrm{dry}, \mathrm{out}}}{\mathrm{T}_{\mathrm{dry}, \text { in }}-\mathrm{T}_{\mathrm{dry}, \mathrm{in}, \mathrm{dp}}}$

where $\varepsilon_{\mathrm{dp}}$ is the dew point effectiveness and $\mathrm{T}_{\mathrm{dry}, \mathrm{in}, \mathrm{dp}}$ is the dew point temperature of the intake air in dry channel.

$\Delta \mathrm{P}=\left(\xi+\lambda_{\mathrm{f}} \frac{1}{\mathrm{Dh}}\right) \frac{\rho \mathrm{U}^{2}}{2}$

where $\Delta \mathrm{P}$ is pressure drop, $\xi$ is coefficient of local resistance, $\lambda_{\mathrm{f}}$ is coefficient of friction resistance, $\mathrm{Dh}$ is hydraulic diameter, $\rho$ is density and $U$ is the air velocity.

\subsubsection{Determination of the operating and performance parameters}

It is important to note that in this study the independent variables are represented by operating parameters and dependent variables are represented by performance parameters. Seven key operating parameters, as shown in Fig. 2, and five performance parameters have been identified to trigger the regression analysis and derive the statistical model for the DPC. The temperature, relative humidity and air flow rate of intake air, and working air fraction over the intake air as flow characteristics and channel height, channel interval and number of layers as geometric characteristics are taken as operating parameters. The reason for selecting these operating parameters lies in the fact that they are the main parameters which can be changed continually during the real DPC operation. Thus, other minor flow and geometric characteristics which are impossible to change during the DPC operation with less importance are not considered. The schematic of the heat and mass exchange are shown in Fig. 3. Five performance parameters to assess the performance of the DPC are cooling capacity, coefficient of performance (COP), pressure drop, dew-point effectiveness and wet-bulb effectiveness.

\subsubsection{Determination of the proper ranges for operating parameters}

To conduct the MPR, range of each operating parameters should be determined. The ranges of each independent variable are listed in Table 2 which have been determined referring to the previously developed lab prototype testing of the DPC [4] and numerical simulation [10]. These ranges will contribute to produce a realistic data set for the model.
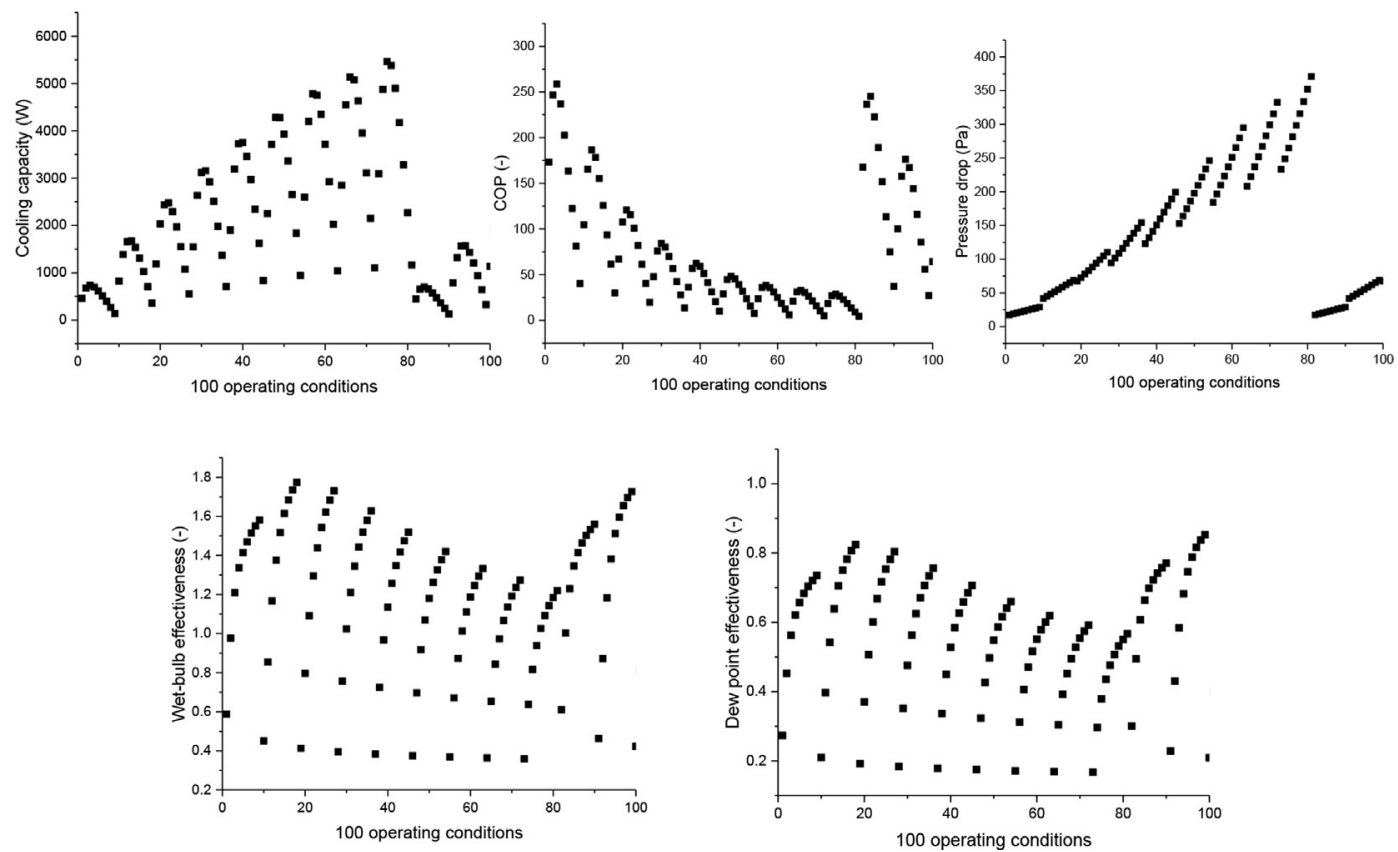

Fig. 5. Relationships between the operating conditions and the corresponding performance parameters. 


\subsubsection{Dataset development}

The comprehensive dataset is divided into two sub sets: 1) training set; 2 ) validation set. $80 \%$ of the comprehensive dataset is selected as the training set and $20 \%$ is selected as the validation set. Training set is used to train and develop the model and validation set is used to validate the developed model. Each set comprises two different parts: 1) Operating parameters; 2) Performance parameters. Discrete values for the operating parameters are needed to construct the independent part of the datasets. The discrete rates of the operating parameters are chosen according to the accuracy and sensitivity of the performance parameters [10]. As it is listed in Table 3 and Table 4, the number of values for each operating parameters for training set and validation set are nine and six respectively. The discrete values of training set will be used once to produce the model only and the model application is not restricted to these values.

All possible combinations of the selected operating parameters which represent all possible operating conditions for the selected discrete values are produced for each set. All possible combinations take all of the probable combinations of the discrete operating parameters into consideration. Thus making the model aware of any random operating conditions. In this study, the total number of operating conditions are 7857 in which $80 \%$ of them, $6561\left(9^{4}\right)$, are chosen for training set and 20\%, $1296\left(6^{4}\right)$, are chosen for the validation set. Fig. 4 shows how $\mathrm{k}$ discreet values of each operating parameters can be combined which only three combinations out of 7857 possible combinations are illustrated here.

Having created the all possible operating conditions, the performance parameters are calculated for each created operating conditions to construct the second part of the dataset. The calculation is done by the numerical model using the created operating conditions and the constant values in Table 5.

Because in real operating conditions, the geometric variables are not changed continually, thus the comprehensive dataset is created for twelve geometric sets to make the final equations more sensible and organized. As can be seen in Table 6 each geometric set has constant geometric parameters including channel height, channel interval and number of layers. All calculations are done by a numerical model previously developed to investigate the novel super performance DPC by authors [10].

\subsubsection{Regression model set up}

Fig. 5 reveals the behavior of the operating conditions versus each performance parameters. It is evident that the MPR is a proper type of regression for DPC data as the relationship between the operating conditions and the corresponding performance parameters can be demonstrated using a curve.

The MPR method was carried out in R software. The general mathematical expression includes the regression coefficients and flow characteristics. The regression coefficients which are derived from the fitting function varies for each geometry sets and thus considers the impact of geometric characteristics. Equation (11) is the general form of the statistical model which is based on the MPR.

$$
\begin{aligned}
\mathrm{Y} & =\beta_{0}+\beta_{1} \times\left(T^{\mathrm{n}_{1,1}} \times \mathrm{RH}^{\mathrm{n}_{2,1}} \times \mathrm{U}^{\mathrm{n}_{3,1}} \times \varphi^{\mathrm{n}_{4,1}}\right)+\beta_{2} \times\left(\mathrm{T}^{\mathrm{n}_{1,2}}\right. \\
& \left.\times \mathrm{RH}^{\mathrm{n}_{2,2}} \times \mathrm{U}^{\mathrm{n}_{3,2}} \times \varphi^{\mathrm{n}_{4,2}}\right)+\ldots+\beta_{\mathrm{m}} \times\left(\mathrm{T}^{\mathrm{n}_{1, \mathrm{~m}}} \times \mathrm{RH}^{\mathrm{n}_{2, \mathrm{~m}}} \times \mathrm{U}^{\mathrm{n}_{3, \mathrm{~m}}}\right. \\
& \left.\times \varphi^{\mathrm{n}_{4, \mathrm{~m}}}\right)
\end{aligned}
$$

where $\mathrm{Y}$ represents the performance parameters, $T, \mathrm{RH}, \mathrm{U}$ and $\varphi$ represent the intake air temperature, relative humidity, air flow velocity and working air fraction over the intake air respectively, $\beta_{1}$, $\beta_{2}, \ldots, \beta_{\mathrm{m}}$ represent the regression coefficients. Power of each independent variable is represented by $n$ in which $n_{1}$ is for intake air temperature, $\mathrm{n}_{2}$ is for intake air relative humidity, $\mathrm{n}_{3}$ is for the air flow velocity, $\mathrm{n}_{4}$ is for the working air fraction over the intake air and the second subscript for $\mathrm{n}$ which is shown by $\mathrm{m}$ is the number of the coefficients. It is important to note that because the operating parameters appear linearly in the equation, thus the regression

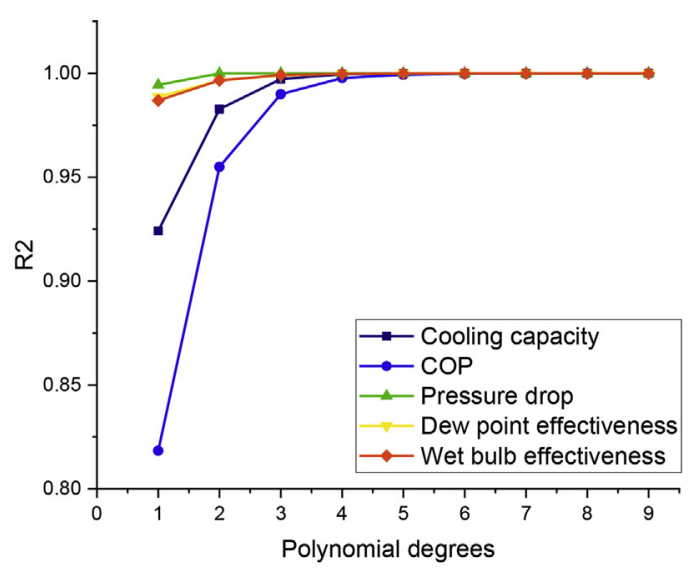

(a)

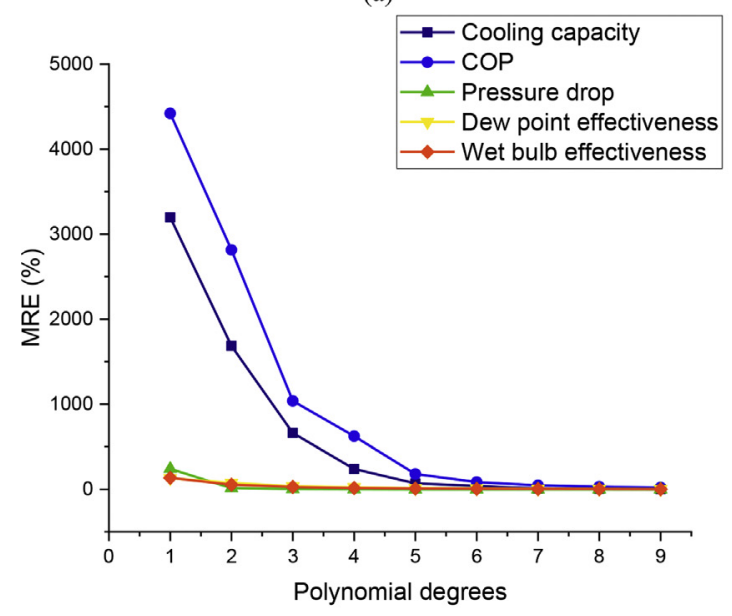

(b)

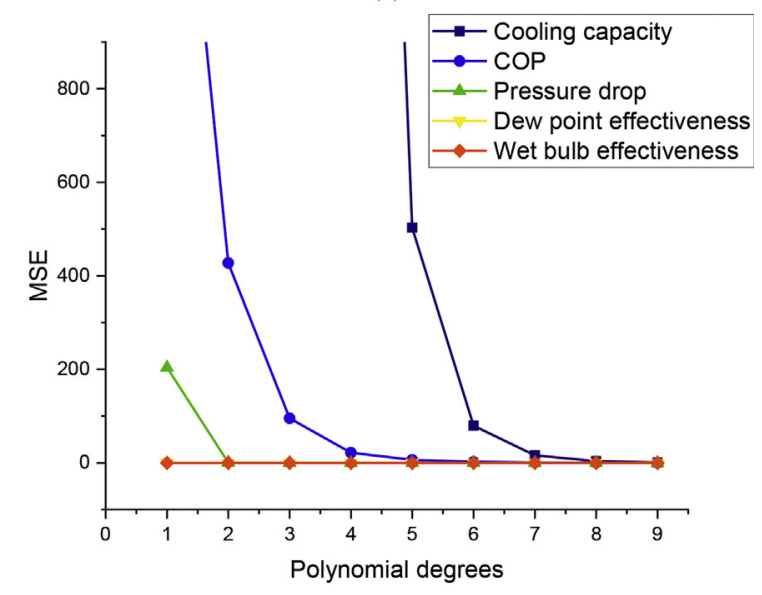

(c)

Fig. 6. Influence of degrees on Metrics: (a): R2; (b): MRE; (c): MSE. 
Table 7

Maximum relative errors of the MPR models.

\begin{tabular}{|c|c|c|c|c|c|c|c|c|c|}
\hline \multirow[t]{2}{*}{ Performance parameters } & \multicolumn{9}{|l|}{ MRE (\%) } \\
\hline & $1 \mathrm{st}$ & 2nd & 3rd & 4th & 5 th & 6 th & 7th & 8 th & 9th \\
\hline Cooling capacity (W) & 3197.36 & 1684.56 & 660.96 & 239.65 & 68.85 & 39.33 & 8.39 & 6.1 & 2.59 \\
\hline $\operatorname{COP}(-)$ & 4421.66 & 2814.83 & 1038.02 & 623.98 & 180.78 & 85.83 & 46.46 & 7.54 & 2.9 \\
\hline Pressure drop (Pa) & 241.04 & 14.34 & 2.42 & 0.6 & 0.21 & 0.12 & 0.086 & 0.07 & 0.07 \\
\hline Dew point effectiveness (\%) & 129.6 & 76.55 & 35.69 & 23.76 & 13.86 & 9.78 & 5.67 & 3.54 & 2.1 \\
\hline Wet bulb effectiveness (\%) & 135.71 & 53.53 & 27.98 & 15.18 & 8.95 & 6.43 & 4.30 & 2.53 & 1.16 \\
\hline
\end{tabular}

model is linear.

\section{Results and discussion}

\subsection{Model assessment}

In this section, nine MPR models with different degrees, i.e., $1 \mathrm{st}$, 2nd, ..., 9th have been considered and compared in order to choose the optimum one, in terms of complexity and accuracy, for performance analysis and design of the DPC system. Accuracy of the MPR model is investigated in two general ways: 1) Changing degree of the polynomial model; 2) Assessing the model performance by different metrics [32]. Model complexity in MPR is controlled by polynomial degrees. Larger degrees allows more complex prediction functions and better fit to training data. However, it does not necessarily lead to better performance of the model. Thus, three common metrics [33], MSE, R2 and MRE, are selected to evaluate the performance of several models with different level of complexities. Five predicted performance parameters are compared with those from the numerical simulation. Firstly, the model results are assessed by $\mathrm{R} 2$ to investigate the level of correlation fitting. As can be seen from Fig. 6(a), the R2 value has sharply increased by increasing the polynomial degrees and has reached 1 for all of the variables from 5th degree afterwards. Although R2 of 1 indicates the good level of fitting, but it does not always lead to a good model. This is because R2 gets higher values by covering more operating parameters so that other metrics are considered in model assessment. As can be seen from Fig. 6(b), the maximum relative errors (MRE) decrease for all variables by increasing the model complexity. The sharp declines show the contribution of the model complexity in enhancement of model accuracy. MSE of $10 \%$ are specified as an acceptable margin in this study and the accepted values are colored in green as listed in Table 7. Thus, in terms of MSE, 7th degree for cooling capacity, 8th degree for COP, 3rd degree for pressure drop, 6th degree for dew point effectiveness and 5th degree for wet-bulb effectiveness can be selected. Therefore, in terms of MSE, increasing the model complexity from aforementioned acceptable degrees leads to more complex model and does not contribute to model accuracy. The trend is exactly the same for the MSE values. As can be seen from Fig. 6(c), MSE for all variables has declined by increasing the model degrees. For dew point and wet-bulb effectiveness, all of the studied models are in favor as the MSE values are close to zero. However, the appropriate models for cooling capacity, COP and pressure drop are 8th degree, 6th degree and 2nd degree respectively as the MSE values have approached zero.

Consequently, having done all of the aforementioned analyses, the accepted models for cooling capacity, COP, pressure drop, dew point and wet-bulb effectiveness are 8 th, 8 th, 5th, 6th and 5th respectively. All other model with higher degrees than the abovementioned accepted degrees are valid and more accurate. Therefore, in order to have a solid single model for all of the five
Table 8

Average errors and r-squared values of 8th degree MPR.

\begin{tabular}{lll}
\hline Dependent variables & R-squared & Average error (\%) \\
\hline Cooling capacity (W) & 1 & 0.09 \\
COP $(-)$ & 1 & 1.22 \\
Pressure drop (Pa) & 1 & 0.01 \\
Dew point effectiveness (\%) & 1 & 0.12 \\
Wet bulb effectiveness (\%) & 0.99 & 0.11 \\
\hline
\end{tabular}

performance parameters, the 8th degree MPR model is taken in next sections to carry out the validation and test parts. Therefore, $\mathrm{r}$ squared values and average relative error values for the selected 8th degree model are given in Table 8. Both r-squared values (0.99-1) and average errors (less than 1.22\%) indicate the quality and accuracy of the 8th degree model.

\subsection{Cross validation}

In this section, cross validation is performed, firstly to validate the selected model and, secondly to check the model overfitting. The model has been generalized through the cross verification. It means that cross verification shows the validity of the proposed model for any new operating condition within the defined ranges. Comparison of the predicted values by 8th degree MPR for each performance parameter with corresponding values derived by numerical model [10] are shown in Fig. 7. The validation is carried out using the validation set and values in Table 5. Channel width, water temperature and water flow rate which have less importance in operation of standard DPC are used to operate the numerical model only. Due to the numerous operating conditions of the validation set, only 20 operating conditions (out of 1296 operating conditions) are illustrated in the Fig. 7.

As can be seen, predicted values by MPR are overlapped with the numerical simulation values whereas the maximum relative errors for cooling capacity, COP, pressure drop, dew point and wet-bulb effectiveness are $1.73 \%, 3.31 \%, 0.05 \%, 3.53 \%$ and $3.48 \%$ respectively. This indicates that MPR model has the satisfactory accuracy and is not over-fitted. Therefore this regression model can be used

Table 9

Powers of general 8th degree polynomial equations.

\begin{tabular}{lllll}
\hline $\mathrm{m}$ & $\mathrm{T}$ & $\frac{\mathrm{RH}}{\mathrm{n}_{2, \mathrm{~m}}}$ & $\frac{\mathrm{U}}{\mathrm{n}_{3, \mathrm{~m}}}$ & $\frac{\phi}{\mathrm{n}_{4, \mathrm{~m}}}$ \\
\hline 1 & 1 & 0 & 0 & 0 \\
2 & 2 & 0 & 0 & 0 \\
3 & 3 & 0 & 0 & 0 \\
$\vdots$ & $\vdots$ & $\vdots$ & $\vdots$ & $\vdots$ \\
494 & 0 & 0 & 0 & 8 \\
\hline
\end{tabular}


Table 10

Coefficients of 8th degree MPR model.

\begin{tabular}{|c|c|c|c|c|c|c|}
\hline \multirow[t]{2}{*}{ Geometric set } & \multirow{2}{*}{$\begin{array}{l}\text { Performance parameters } \\
\mathrm{Y}\end{array}$} & \multirow{2}{*}{$\frac{\mathrm{m}=0}{\beta_{0}}$} & \multirow{2}{*}{$\begin{array}{l}\mathrm{m}=1 \\
\beta_{1}\end{array}$} & \multirow{2}{*}{$\mathrm{m}=2$} & \multirow{2}{*}{$\frac{\cdots}{\mathrm{B}_{\mathrm{m}}}$} & \multirow{2}{*}{$\begin{array}{l}M=494 \\
\beta_{494}\end{array}$} \\
\hline & & & & & & \\
\hline \multirow[t]{5}{*}{1} & $\mathrm{Q}_{\text {cooling }}$ & $3.807 e+04$ & $-9.006 e+03$ & $9.193 e+02$ & $\ldots$ & $-5.059 e+04$ \\
\hline & $\mathrm{COP}$ & $-2.354 \mathrm{e}+03$ & $5.113 e+0$ & $-4.893 e+01$ & $\ldots$ & $-3.128 \mathrm{e}+03$ \\
\hline & $\Delta \mathrm{P}$ & $1.298 \mathrm{e}+03$ & $-2.627 e+02$ & $2.284 \mathrm{e}+01$ & $\ldots$ & $-1.718 e+02$ \\
\hline & $\varepsilon_{\mathrm{dp}}$ & $3.483 e+02$ & $-8.201 \mathrm{e}+01$ & $8.251 \mathrm{e}+00$ & $\ldots$ & $-1.368 \mathrm{e}+01$ \\
\hline & $\varepsilon_{\mathrm{wb}}$ & $-4.996 e+01$ & $1.133 e+0$ & $-1.124 \mathrm{e}+00$ & $\ldots$ & $-9.738 \mathrm{e}+00$ \\
\hline \multirow[t]{5}{*}{2} & $\mathrm{Q}_{\text {cooling }}$ & $3.118 \mathrm{e}+03$ & $1.048 \mathrm{e}+03$ & $1.092 \mathrm{e}+02$ & $\ldots$ & $-6.689 e+04$ \\
\hline & $\mathrm{COP}$ & $-2.287 e+03$ & $5.186 e+02$ & $-5.254 \mathrm{e}+01$ & $\ldots$ & $-4.727 e+03$ \\
\hline & $\Delta \mathrm{P}$ & $-1.661 \mathrm{e}+02$ & $1.046 \mathrm{e}+02$ & $-1.708 \mathrm{e}+0$ & $\ldots$ & $5.501 \mathrm{e}+01$ \\
\hline & $\varepsilon_{\mathrm{dp}}$ & $3.661 \mathrm{e}+02$ & $-8.634 \mathrm{e}+01$ & $8.701 \mathrm{e}+00$ & $\ldots$ & $-7.692 \mathrm{e}+00$ \\
\hline & $\varepsilon_{\mathrm{wb}}$ & $-3.839 e+01$ & $8.032 \mathrm{e}+00$ & $-7.435 \mathrm{e}-01$ & $\ldots$ & $-4.384 \mathrm{e}+00$ \\
\hline \multirow[t]{5}{*}{3} & $\mathrm{Q}_{\text {cooling }}$ & $-4.378 e+03$ & $1.075 e+03$ & $-1.065 e+02$ & $\ldots$ & $-1.151 e+05$ \\
\hline & $\mathrm{COP}$ & $-1.016 e+03$ & $2.057 e+02$ & $-1.946 e+01$ & $\ldots$ & $-7.906 e+03$ \\
\hline & $\Delta \mathrm{P}$ & $2.590 \mathrm{e}+02$ & $-6.177 e+01$ & $6.359 e+00$ & $\ldots$ & $4.164 \mathrm{e}+01$ \\
\hline & $\varepsilon_{\mathrm{dp}}$ & $2.652 \mathrm{e}+02$ & $-6.249 e+01$ & $6.297 e+00$ & $\ldots$ & $-1.895 e+01$ \\
\hline & $\varepsilon_{\mathrm{wb}}$ & $-1.707 e+01$ & $3.785 e+00$ & $-3.788 \mathrm{e}-01$ & $\ldots$ & $-2.939 e+01$ \\
\hline \multirow[t]{5}{*}{4} & $\mathrm{Q}_{\text {cooling }}$ & $-3.821 e+02$ & $-2.462 \mathrm{e}+02$ & $8.092 \mathrm{e}+01$ & $\ldots$ & $-2.372 \mathrm{e}+05$ \\
\hline & $\mathrm{COP}$ & $2.903 e+03$ & $-6.294 e+02$ & $6.052 \mathrm{e}+01$ & $\ldots$ & $-7.800 e+03$ \\
\hline & $\Delta \mathrm{P}$ & $3.051 \mathrm{e}+03$ & $-7.324 \mathrm{e}+02$ & $7.660 \mathrm{e}+01$ & $\ldots$ & $2.071 \mathrm{e}+02$ \\
\hline & $\varepsilon_{\mathrm{dp}}$ & $2.387 e+02$ & $-5.608 e+01$ & $5.630 \mathrm{e}+00$ & $\ldots$ & $-1.610 e+01$ \\
\hline & $\varepsilon_{\mathrm{wb}}$ & $-1.453 e+01$ & $3.461 \mathrm{e}+00$ & $-3.493 e-01$ & $\ldots$ & $-2.125 \mathrm{e}+01$ \\
\hline \multirow[t]{5}{*}{5} & $\mathrm{Q}_{\text {cooling }}$ & $1.351 \mathrm{e}+04$ & $-3.454 e+03$ & $3.597 e+02$ & $\ldots$ & $8.692 \mathrm{e}+03$ \\
\hline & $\mathrm{COP}$ & $-6.549 e+02$ & $1.348 \mathrm{e}+02$ & $-1.280 \mathrm{e}+01$ & $\ldots$ & $-1.162 e+03$ \\
\hline & $\Delta \mathrm{P}$ & $1.026 e+03$ & $-2.475 e+02$ & $2.590 \mathrm{e}+01$ & $\ldots$ & $3.402 \mathrm{e}+01$ \\
\hline & $\varepsilon_{\mathrm{dp}}$ & $3.906 e+02$ & $-9.235 e+01$ & $9.328 \mathrm{e}+00$ & $\ldots$ & $9.135 \mathrm{e}+00$ \\
\hline & $\varepsilon_{\mathrm{wb}}$ & $2.461 \mathrm{e}+00$ & $-7.326 e-01$ & $7.598 \mathrm{e}-02$ & $\ldots$ & $2.712 \mathrm{e}+01$ \\
\hline \multirow[t]{5}{*}{6} & $\mathrm{Q}_{\text {cooling }}$ & $-1.248 \mathrm{e}+04$ & $1.512 \mathrm{e}+03$ & $-9.795 e+01$ & $\ldots$ & $1.076 \mathrm{e}+05$ \\
\hline & $\mathrm{COP}$ & $-1.485 e+02$ & $1.117 \mathrm{e}+01$ & $-4.411 \mathrm{e}-01$ & $\ldots$ & $-2.809 e+03$ \\
\hline & $\Delta \mathrm{P}$ & $-2.296 e+03$ & $4.556 e+02$ & $-3.865 e+01$ & $\ldots$ & $9.069 \mathrm{e}+01$ \\
\hline & $\varepsilon_{\mathrm{dp}}$ & $1.017 \mathrm{e}+02$ & $-2.411 \mathrm{e}+01$ & $2.298 \mathrm{e}+00$ & $\ldots$ & $2.107 e+01$ \\
\hline & $\varepsilon_{\mathrm{wb}}$ & $-8.642 \mathrm{e}+00$ & $1.014 \mathrm{e}+00$ & $-4.549 \mathrm{e}-02$ & $\ldots$ & $4.398 \mathrm{e}+01$ \\
\hline \multirow[t]{5}{*}{7} & $\mathrm{Q}_{\text {cooling }}$ & $-1.278 \mathrm{e}+04$ & $3.001 \mathrm{e}+03$ & $-3.134 \mathrm{e}+02$ & $\ldots$ & $-1.183 e+05$ \\
\hline & $\mathrm{COP}$ & $3.071 \mathrm{e}+03$ & $-6.890 e+02$ & $6.563 e+01$ & $\ldots$ & $-6.401 e+03$ \\
\hline & $\Delta \mathrm{P}$ & $-4.816 e+03$ & $1.144 \mathrm{e}+03$ & $-1.172 \mathrm{e}+02$ & $\ldots$ & $-8.053 e+01$ \\
\hline & $\varepsilon_{\mathrm{dp}}$ & $3.157 e+02$ & $-7.450 \mathrm{e}+01$ & $7.516 e+00$ & $\ldots$ & $-1.827 e+01$ \\
\hline & $\varepsilon_{\mathrm{wb}}$ & $-5.186 e+00$ & $1.160 \mathrm{e}+00$ & $-1.229 \mathrm{e}-01$ & $\ldots$ & $-2.137 e+01$ \\
\hline \multirow[t]{5}{*}{8} & $\mathrm{Q}_{\text {cooling }}$ & $-1.401 \mathrm{e}+04$ & $3.315 e+03$ & $-3.284 \mathrm{e}+02$ & $\ldots$ & $-2.136 e+05$ \\
\hline & $\mathrm{COP}$ & $1.377 \mathrm{e}+03$ & $-2.511 \mathrm{e}+02$ & $2.489 e+01$ & $\ldots$ & $-1.714 e+03$ \\
\hline & $\Delta \mathrm{P}$ & $2.640 \mathrm{e}+02$ & $-3.346 e+01$ & $5.031 \mathrm{e}-01$ & $\ldots$ & $7.573 e+01$ \\
\hline & $\varepsilon_{\mathrm{dp}}$ & $3.337 e+02$ & $-7.868 \mathrm{e}+01$ & $7.944 \mathrm{e}+00$ & $\ldots$ & $-2.812 \mathrm{e}+00$ \\
\hline & $\varepsilon_{\mathrm{wb}}$ & $-1.621 \mathrm{e}+01$ & $3.606 \mathrm{e}+00$ & $-3.269 \mathrm{e}-01$ & $\ldots$ & $2.961 \mathrm{e}+00$ \\
\hline 9 & $\mathrm{Q}_{\text {cooling }}$ & $1.596 e+04$ & $-4.310 e+03$ & $4.504 \mathrm{e}+02$ & $\ldots$ & $7.089 e+04$ \\
\hline & $\mathrm{COP}$ & $1.765 \mathrm{e}+02$ & $-7.621 e+01$ & $1.014 \mathrm{e}+01$ & $\ldots$ & $-3.743 e+02$ \\
\hline & $\Delta \mathrm{P}$ & $7.107 e+03$ & $-1.897 e+03$ & $2.157 e+02$ & $\ldots$ & $-6.753 e+02$ \\
\hline & $\varepsilon_{\mathrm{dp}}$ & $4.144 \mathrm{e}+02$ & $-9.783 e+01$ & $9.872 \mathrm{e}+00$ & $\ldots$ & $2.994 \mathrm{e}+01$ \\
\hline & $\varepsilon_{\mathrm{wb}}$ & $2.766 \mathrm{e}+01$ & $-7.527 e+00$ & $8.420 \mathrm{e}-01$ & $\ldots$ & $6.029 e+01$ \\
\hline 10 & $\mathrm{Q}_{\text {cooling }}$ & $-1.251 \mathrm{e}+04$ & $8.453 e+02$ & $-3.641 e+01$ & $\ldots$ & $2.437 e+05$ \\
\hline & $\mathrm{COP}$ & $-6.748 e+02$ & $1.053 e+02$ & $-6.987 e+00$ & $\ldots$ & $-1.935 e+03$ \\
\hline & $\Delta \mathrm{P}$ & $-6.303 e+03$ & $1.287 \mathrm{e}+03$ & $-1.089 e+02$ & $\ldots$ & $-7.345 e+02$ \\
\hline & $\varepsilon_{\mathrm{dp}}$ & $4.235 \mathrm{e}+02$ & $-1.009 e+02$ & $1.025 e+01$ & $\ldots$ & $4.747 e+01$ \\
\hline & $\varepsilon_{\mathrm{wb}}$ & $-3.157 e+0$ & $5.909 \mathrm{e}+00$ & $-5.084 \mathrm{e}-0$ & $\ldots$ & $8.068 \mathrm{e}+01$ \\
\hline 11 & $\mathrm{Q}_{\text {cooling }}$ & $-3.305 e+04$ & $8.131 \mathrm{e}+03$ & $-8.888 e+02$ & $\ldots$ & $-9.191 e+04$ \\
\hline & $\mathrm{COP}$ & $5.614 \mathrm{e}+0$ & $-1.372 \mathrm{e}+02$ & $1.327 \mathrm{e}+01$ & $\ldots$ & $-4.929 e+03$ \\
\hline & $\Delta \mathrm{P}$ & $6.201 \mathrm{e}+02$ & $-1.663 e+02$ & $1.865 e+01$ & $\ldots$ & $-2.395 e+01$ \\
\hline & $\varepsilon_{\mathrm{dp}}$ & $3.404 \mathrm{e}+02$ & $-8.030 \mathrm{e}+01$ & $8.090 \mathrm{e}+00$ & $\ldots$ & $-1.138 \mathrm{e}+01$ \\
\hline & $\varepsilon_{\mathrm{wb}}$ & $2.566 \mathrm{e}+01$ & $-5.993 e+00$ & $6.013 e-0$ & $\ldots$ & $-1.016 \mathrm{e}+01$ \\
\hline 12 & $\mathrm{Q}_{\text {cooling }}$ & $-1.920 \mathrm{e}+04$ & $3.678 e+03$ & $-3.309 e+02$ & $\ldots$ & $-1.104 \mathrm{e}+05$ \\
\hline & $\mathrm{COP}$ & $-1.318 \mathrm{e}+0$ & $1.283 e+02$ & $-1.574 \mathrm{e}+01$ & $\ldots$ & $1.845 e+03$ \\
\hline & $\Delta \mathrm{P}$ & $7.786 e+03$ & $-1.816 e+03$ & $1.850 \mathrm{e}+02$ & $\ldots$ & $-1.772 e+02$ \\
\hline & $\varepsilon_{\mathrm{dp}}$ & $3.655 e+02$ & $-8.615 e+01$ & $8.692 \mathrm{e}+00$ & $\ldots$ & $1.182 \mathrm{e}+01$ \\
\hline & $\varepsilon_{\mathrm{wb}}$ & $-1.285 e+01$ & $3.215 \mathrm{e}+00$ & $-3.287 e-01$ & $\ldots$ & $1.825 \mathrm{e}+01$ \\
\hline
\end{tabular}

to replace the previous numerical and experimental models to predict the performance of the DPC.

\subsection{Polynomial equations}

The comprehensive MPR model obtained for the DPC is presented in Equation (12), which is the generalized form of Equation
Table 11

Random operating parameters.

\begin{tabular}{lllll}
\hline No. Of discreet values & $\mathrm{T}\left({ }^{\circ} \mathrm{C}\right)$ & $\mathrm{RH}(-)$ & $\mathrm{U}(\mathrm{m} / \mathrm{s})$ & $\phi(-)$ \\
\hline 1 & 33.75 & 0.28 & 1.7 & 0.45 \\
2 & 36.25 & 0.32 & 2.1 & 0.55 \\
3 & 38.75 & 0.36 & 2.5 & 0.65 \\
\hline
\end{tabular}



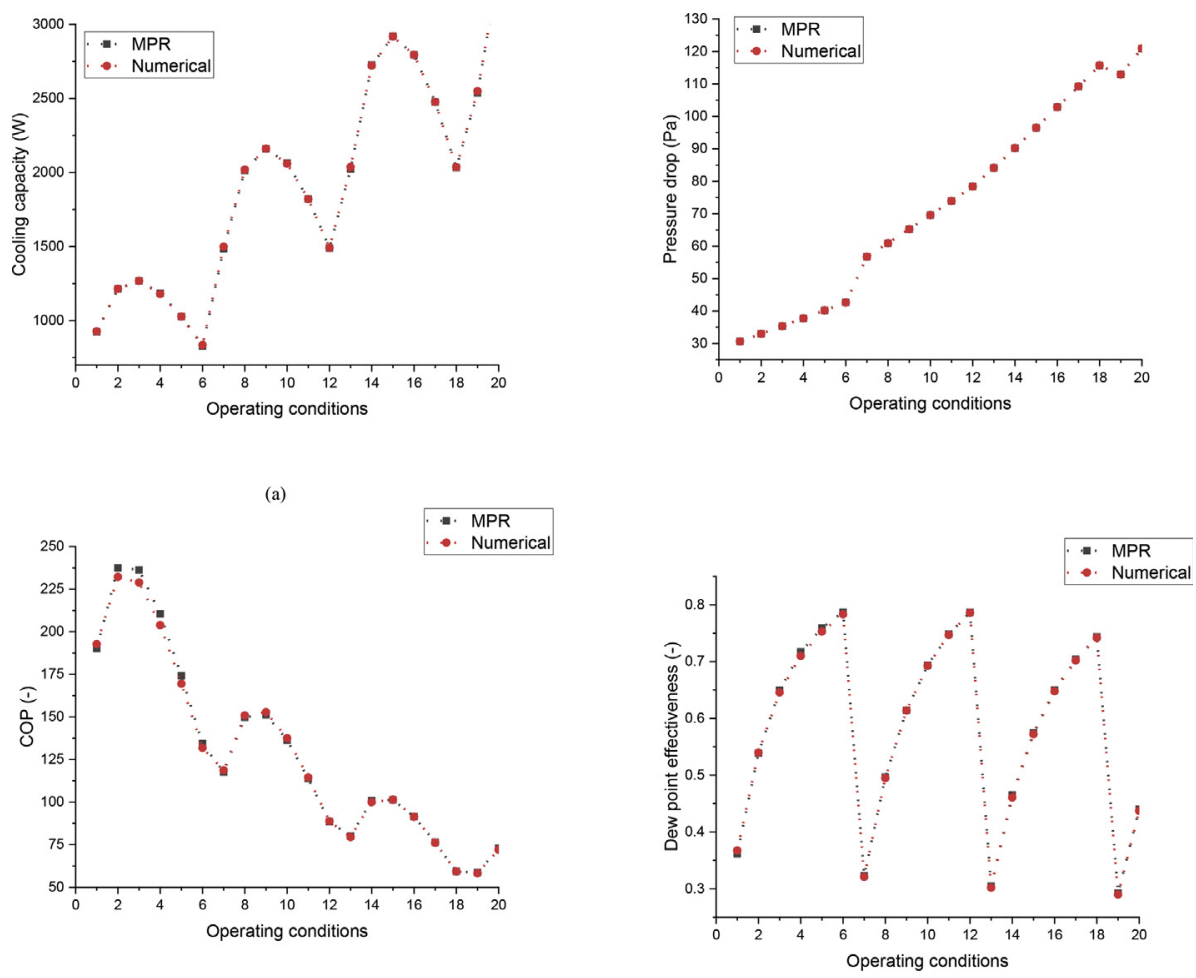

(c)

(d)

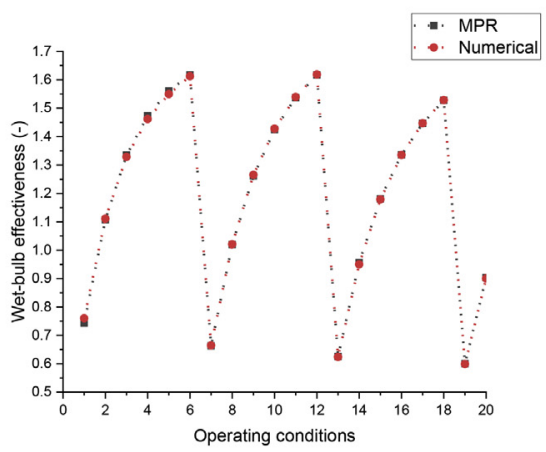

Fig. 7. Cross verifications: (a): Cooling capacity; (b): Pressure drop; (c): COP; (d): Dew-point effectiveness; (e): Wet-bulb effectiveness.

(11). The matrix on the left of equal sign represents the performance parameters and on the two first matrices on right side of equal sign, represent the regression coefficients and third matrix represents the operating parameters. Power of each independent variable is denoted by $\mathrm{n}$ in which $\mathrm{n}_{1}$ is for intake air temperature, $\mathrm{n}_{2}$ is for intake air relative humidity, $\mathrm{n}_{3}$ is for the air flow velocity, $\mathrm{n}_{4}$ is for the working air fraction over the intake air and the second subscript for $n$ which is shown by $m$ indicates the number of

$$
\left[\begin{array}{c}
\mathrm{Q}_{\text {cooling }} \\
\text { COP } \\
\varepsilon_{\mathrm{wb}} \\
\varepsilon_{\mathrm{dp}}
\end{array}\right]=\left[\begin{array}{l}
\beta_{0,1} \\
\beta_{0,2} \\
\beta_{0,3} \\
\beta_{0,4} \\
\beta_{0,5}
\end{array}\right]+\left[\begin{array}{ccccc}
\beta_{1,1} & \beta_{1,2} & \beta_{1,3} & \cdots & \beta_{1, \mathrm{~m}} \\
\beta_{2,1} & \beta_{2,2} & \beta_{2,3} & \cdots & \beta_{2, \mathrm{~m}} \\
\beta_{3,1} & \beta_{3,2} & \beta_{3,3} & \cdots & \beta_{3, \mathrm{~m}} \\
\beta_{4,1} & \beta_{4,2} & \beta_{4,3} & \cdots & \vdots \\
\beta_{5,1} & \beta_{5,2} & \beta_{5,3} & \cdots & \beta_{5, \mathrm{~m}}
\end{array}\right]\left[\begin{array}{c}
\mathrm{T}^{\mathrm{n}_{1,1}} \times \mathrm{RH}^{\mathrm{n}_{2,1}} \times \mathrm{U}^{\mathrm{n}_{3,1}} \times \varphi^{\mathrm{n}_{4,1}} \\
\mathrm{~T}^{\mathrm{n}_{1,2}} \times \mathrm{RH}^{\mathrm{n}_{2,2}} \times \mathrm{U}^{\mathrm{n}_{3,2}} \times \varphi^{\mathrm{n}_{4,2}} \\
\mathrm{~T}^{\mathrm{n}_{1,3}} \times \mathrm{RH}^{\mathrm{n}_{2,3}} \times \mathrm{U}^{\mathrm{n}_{3,3}} \times \varphi^{\mathrm{n}_{4,3}} \\
\vdots \\
\mathrm{T}^{\mathrm{n}_{1, \mathrm{~m}}} \times \mathrm{RH}^{\mathrm{n}_{2, \mathrm{~m}}} \times \mathrm{U}^{\mathrm{n}_{3, \mathrm{~m}}} \times \varphi^{\mathrm{n}_{4, \mathrm{~m}}}
\end{array}\right]
$$




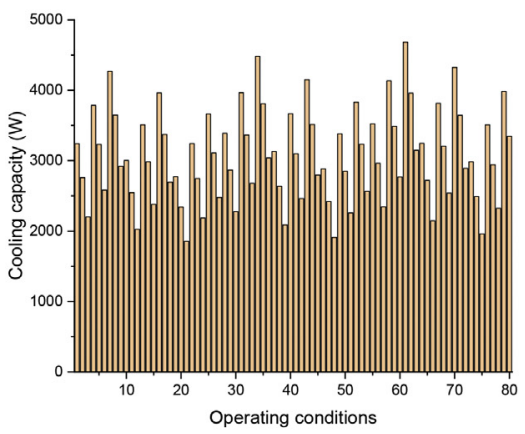

(a)

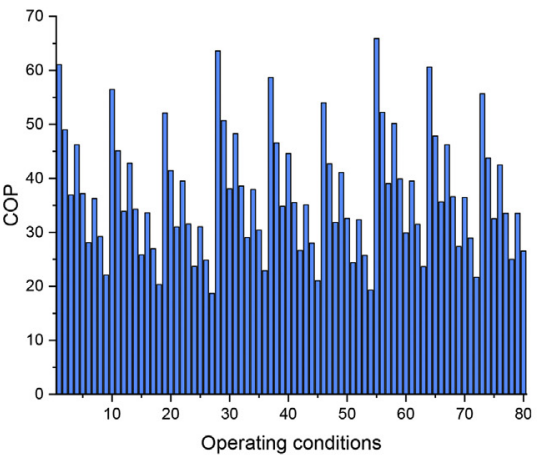

(b)

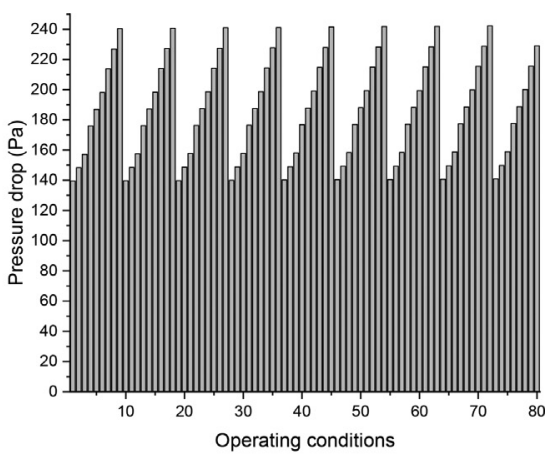

(c)

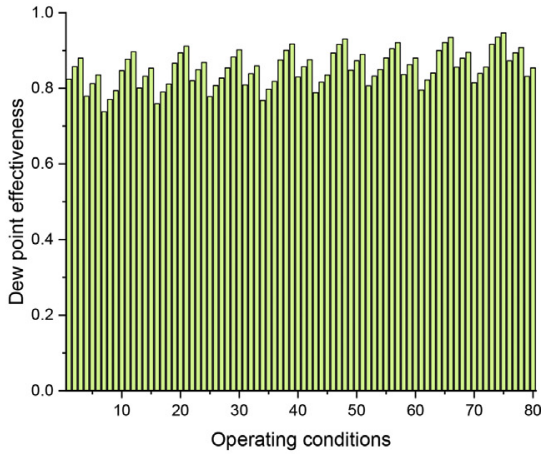

(d)

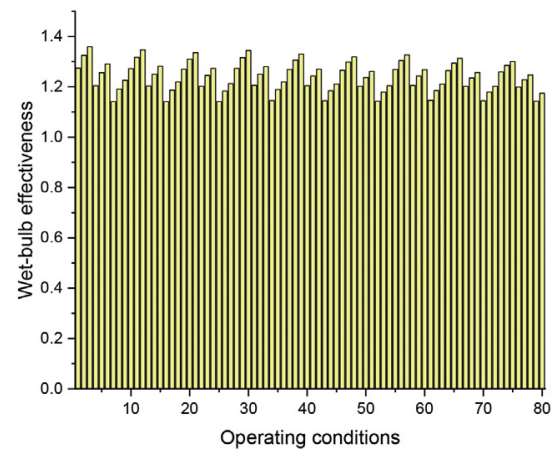

(e)

Fig. 8. DPC performance in the random operating conditions: (a): Cooling capacity; (b): Pressure drop; (c): COP; (d): Dew-point effectiveness; (e): Wet-bulb effectiveness.

coefficients. The number of coefficients for $\mathrm{N}^{\text {th }}$ degree polynomial with k variables is $\left(\begin{array}{c}k+N \\ N\end{array}\right)-1$, which is 494 for 8 th degree model with four operating parameters. It is important to mention that the corresponding powers for each coefficient in general 8th degree polynomial are listed in Table 9.

The equation varies for different operating conditions and for different geometric sets. Table 10 gives all the regression coefficients to construct the 8th degree polynomial equations for different geometric sets. The equations for five performance parameters can be used by substituting the proper coefficients in Equation (12) and thus the performance analysis of the DPC is possible for any operating conditions by considering the provided ranges in Table 2 . Since the total number of the coefficients for each performance parameter are 494, thus the table is summarized.

\subsection{Applications of the developed model}

In this section, two applications of the developed MPR model are presented. In the first case, the performance of the DPC is predicted and discussed under random operating conditions. Then, 


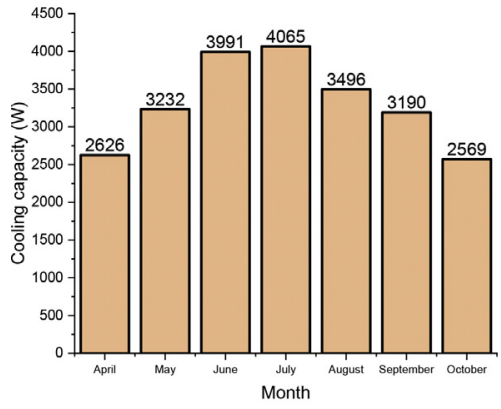

(a)

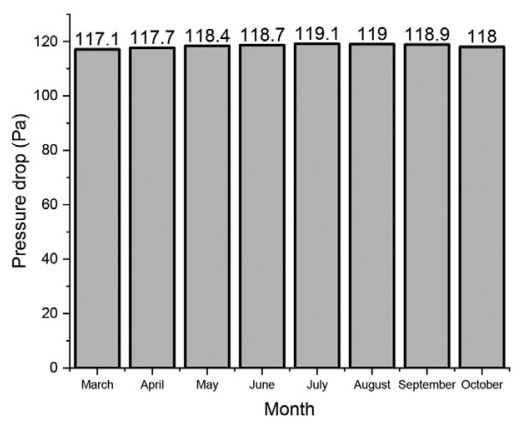

(c)

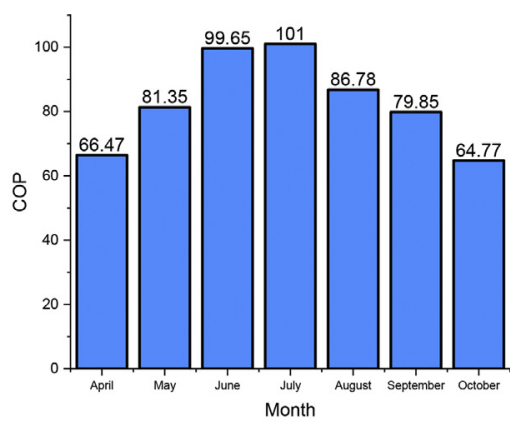

(b)

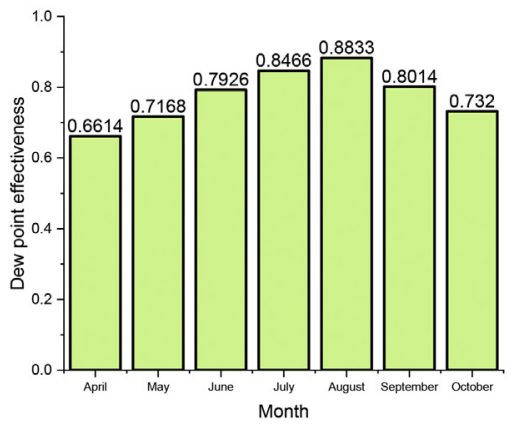

(d)

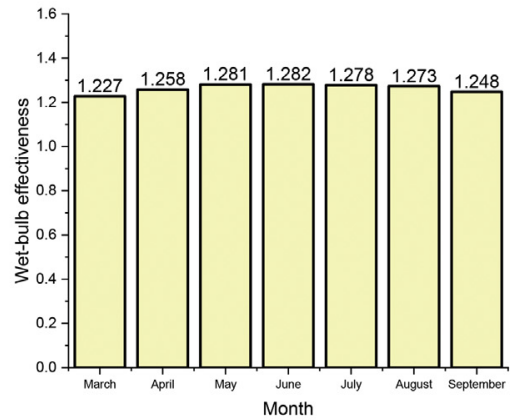

Fig. 9. Predicted performance of the DPC in Las Vegas: (a): Cooling capacity; (b): Pressure drop; (c): COP; (d): Dew-point effectiveness; (e): Wet-bulb effectiveness.

Table 12

Average weather information in Las Vegas.

\begin{tabular}{lll}
\hline Month & $\mathrm{T}\left({ }^{\circ} \mathrm{C}\right)$ & $\mathrm{RH}(-)$ \\
\hline April & 25 & 0.25 \\
May & 30 & 0.21 \\
June & 37 & 0.18 \\
July & 40 & 0.2 \\
August & 39 & 0.27 \\
September & 33 & 0.26 \\
October & 27 & 0.3 \\
\hline
\end{tabular}

the average monthly weather conditions of a dry climate is taken as the second case to present another application of the MPR model. The geometric set 2 is selected as dimensions of the system. The DPC system performance will be predicted for aforementioned cases by Equation (13) which is achieved through substituting the coefficients of geometric set 2, from Table 10, in Equation (12) and by applying the listed powers in Table 9. Values of operating parameters will be substituted according to the operating conditions in each application. 
$\left[\begin{array}{c}\mathrm{Q}_{\text {cooling }} \\ \mathrm{COP} \\ \varepsilon_{\mathrm{wb}} \\ \varepsilon_{\mathrm{dp}} \\ \Delta \mathrm{P}\end{array}\right]=\left[\begin{array}{c}+3.118 \mathrm{e}+03 \\ -2.287 \mathrm{e}+03 \\ -1.661 \mathrm{e}+02 \\ +3.661 \mathrm{e}+02 \\ -3.839 \mathrm{e}+01\end{array}\right]+$

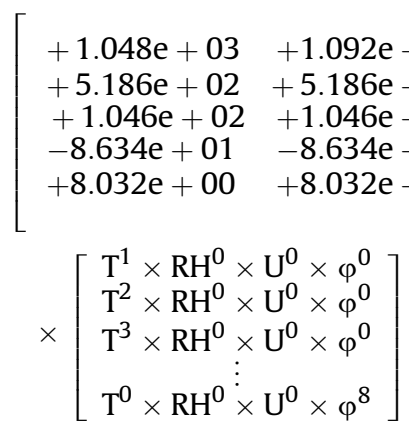

\subsubsection{Prediction of the DPC performance in random conditions}

Random operating conditions are created using Table 11. The performance results of the DPC system are given in Fig. 8. As can be seen, the cooling capacity, COP, pressure drop, dew point and wetbulb effectiveness of the system are predicted for the selected conditions. The cooling capacity varies from 1857 (W) to 4693 (W) in which the minimum and maximum cooling capacity values are predicted to occur at 21st and 61st operating conditions. Similarly, COP is predicted to change from 18.7 in 27 th condition to 65.91 in 55th condition, pressure drop is predicted to change from 139.5 (Pa) in 1st condition to $242.6(\mathrm{~Pa})$ in 81 st condition, dew point effectiveness is predicted to change from 0.73 in 7 th condition to 0.94 in 75th condition and eventually the wet-bulb effectiveness is predicted to vary from 1.14 in 7 th condition to 1.35 in 3 rd condition.

\subsubsection{Prediction of the DPC performance in a dry climate}

The model is used to predict the performance of the DPC in a city with a dry and hot climate i.e. Las Vegas. Seven months with relatively low average humidity levels [34] are selected in which the DPC can perform without any pretreatment as listed in Table 12. Intake air flow rate and the working air fraction over the intake air are selected to be $1.5(\mathrm{~m} / \mathrm{s})$ and 0.4 respectively.

The prediction of the DPC performance for the Las Vegas is given in Fig. 9. As can be seen, the DPC has the best performance in terms of cooling capacity and COP in June, July and August. The maximum cooling capacity and maximum COP are predicted to obtain in July which are 4065 (W) and 101 respectively. This is mainly because of the high temperature of July when it is around $40^{\circ} \mathrm{C}$. The pressure drop is relatively same during the operation and has reached the maximum level of 118 (Pa) in August. The maximum dew point effectiveness is occurred in August which is 0.88 (88\%) and the maximum wet-bulb effectiveness is predicted to happen in July which is 1.28 (1.28\%). On the other hand the DPC has the worst performance in April and October where all of the performance parameters have reached their minimum levels.

\section{Conclusions}

A statistical model based on multiple polynomial regression (MPR) method was presented to predict the performance of a DPC with a novel irregular heat and mass exchanger. Such kind of effort in bringing the MPR into the DPC technology adds important scientific values to characterization of the engineering process of the DPC. The model is first trained and developed by a training set and then validated with a previously developed numerical model by a validation set. The multiple polynomial regression approach has explored lots of numerical and experimental data and produced the statistical model, and directly correlated the selected parameters. The selected operating parameters were intake air conditions, including temperature, relative humidity and flow rate as well as the working air fraction over the intake air. The performance parameters were cooling capacity, coefficient of performance (COP), pressure drop, dew point effectiveness and wet-bulb effectiveness. Additionally, model was classified in different geometric sets by considering the channel height, channel interval and number of layers in heat and mass exchanger as geometric characteristics. The model is also assessed by three common metrics i.e. R2, MSE and MRE for different polynomial degrees and the 8th degree polynomial was selected to perform in this study. The selected 8th degree model can predict the performance of the DPC with $6.1 \%$, $7.54 \%, 0.07 \%, 3.53 \%$ and $2.53 \%$ discrepancies for cooling capacity, COP, pressure drop, dew point and wet-bulb effectiveness respectively. The presented regression model is swift in operation and can be used in prediction, optimization and design of the DPC to commercialize this technology.

This study has focused on prediction of the DPC performance under different operating conditions. In the future studies, the model can be employed to find the optimum geometric and flow characteristics of the DPC system in different climates and operating conditions.

\section{Acknowledgements}

The authors would acknowledge our sincere appreciation to the financial supports from the European Commission H2020 MSCA programme (for the EU H2020-MSCA-RISE-2016-734340 DEWCOOL-4-CDC project) and Royal Academy of Engineering (for the UK-CIAPPn415 project).

\section{References}

[1] Duan Z, et al. Indirect evaporative cooling: past, present and future potentials Renew Sustain Energy Rev 2012;16(9):6823-50.

[2] Maisotsenko V, et al. Method and plate apparatus for dew point evaporative cooler. Google Patents; 2003.

[3] Zhan C, et al. Comparative study of the performance of the M-cycle counterflow and cross-flow heat exchangers for indirect evaporative cooling-paving the path toward sustainable cooling of buildings. Energy 2011;36(12): 6790-805.

[4] Xu P, et al. Experimental investigation of a super performance dew point air cooler. Appl Energy 2017:203:761-77.

[5] Bruno F. On-site experimental testing of a novel dew point evaporative cooler Energy Build 2011;43(12):3475-83.

[6] Riangvilaikul B, Kumar S. An experimental study of a novel dew point evaporative cooling system. Energy Build 2010;42(5):637-44.

[7] Zhao X, Li J, Riffat S. Numerical study of a novel counter-flow heat and mass exchanger for dew point evaporative cooling. Appl Therm Eng 2008:28(14-15):1942-51.

[8] Cui X, Chua K, Yang W. Numerical simulation of a novel energy-efficient dewpoint evaporative air cooler. Appl Energy 2014;136:979-88.

[9] Lin J, et al. Unsteady-state analysis of a counter-flow dew point evaporative cooling system. Energy 2016;113:172-85.

[10] Xu P, et al. Numerical investigation of the energy performance of a guideless irregular heat and mass exchanger with corrugated heat transfer surface for dew point cooling. Energy 2016;109:803-17.

[11] Lin J, et al. Study on dew point evaporative cooling system with counter-flow configuration. Energy Convers Manag 2016;109:153-65.

[12] Riangvilaikul B, Kumar S. Numerical study of a novel dew point evaporative cooling system. Energy Build 2010;42(11):2241-50.

[13] Wan Y, et al. Similarity analysis and comparative study on the performance of counter-flow dew point evaporative coolers with experimental validation, vol. 169; 2018. p. 97-110.

[14] Lin J, et al. On the fundamental heat and mass transfer analysis of the counterflow dew point evaporative cooler, vol. 217; 2018. p. 126-42.

[15] Lin J, et al. Multivariate scaling and dimensional analysis of the counter-flow 
dew point evaporative cooler, vol. 150; 2017. p. 172-87.

[16] Pandelidis D, Anisimov S, Transfer M. Application of a statistical design fo analyzing basic performance characteristics of the cross-flow Maisotsenko cycle heat exchanger, vol. 95; 2016. p. 45-61.

[17] Cui X, et al. Developing a performance correlation for counter-flow regenerative indirect evaporative heat exchangers with experimental validation, vol. 108; 2016. p. 774-84.

[18] Sohani A, Sayyaadi H, Hoseinpoori S. Modeling and multi-objective optimization of an M-cycle cross-flow indirect evaporative cooler using the GMDH type neural network. Int J Refrig 2016;69:186-204.

[19] Sohani A, et al. Comparative study of the conventional types of heat and mass exchangers to achieve the best design of dew point evaporative coolers at diverse climatic conditions, vol. 158; 2018. p. 327-45.

[20] Sohani A, et al. A novel approach using predictive models for performance analysis of desiccant enhanced evaporative cooling systems, vol.107; 2016. p. $227-52$.

[21] Sohani A, et al. A comprehensive performance investigation of cellulose evaporative cooling pad systems using predictive approaches, vol.110; 2017. p. $1589-608$.

[22] Sohani A, et al. A systematic approach to find the best road map for enhancement of a power plant with dew point inlet air pre-cooling of the air compressor, vol.150; 2017. p. 463-84.

[23] Comino F, et al. Simplified performance correlation of an indirect evaporative cooling system. Development and validation 2018;88:307-17.

[24] Dizaji HS, et al. Development and validation of an analytical model for perforated (multi-stage) regenerative M-cycle air cooler, vol.228; 2018. p. 2176-94.

[25] López-Belchí A, et al. GMDH ANN to optimise model development: prediction of the pressure drop and the heat transfer coefficient during condensation within mini-channels, vol. 144; 2018. p. 321-30.

[26] Pakari A, Ghani S. Regression models for performance prediction of counter flow dew point evaporative cooling systems. Energy Conversion and Management 2019;185:562-73.

[27] Moustris K, et al. Application of multiple linear regression models and artificial neural networks on the surface ozone forecast in the greater Athens area, Greece. Advances in Meteorology 2012:8. https://doi.org/10.1155/2012/ 894714. 2012.

[28] Prentice RL, Gloeckler LA. Regression analysis of grouped survival data with application to breast cancer data. Biometrics; 1978. p. 57-67.

[29] Orme JG, Combs-Orme T. Multiple regression with discrete dependent variables. Oxford University Press; 2009.

[30] Weisberg S. Applied linear regression, vol. 528. John Wiley \& Sons; 2005.

[31] Handbook AF. American society of heating, refrigerating and air-conditioning engineers. Atlanta, GA, USA: Inc.; 2009.

[32] Chatterjee S, Hadi AS. Regression analysis by example. John Wiley \& Sons; 2015.

[33] Ostertagová E. Modelling using polynomial regression. Procedia Engineering 2012;48:500-6.

[34] Climate and average monthly weather in Las Vegas. 2019. https://weatherand-climate.com. 